\title{
Partial Nephrectomy Versus Radical Nephrectomy for Localized Renal Masses: Critical Analysis of Oncological Outcome and Impact on the Renal Function Mohamed Selim, Mahmoud Amer*, Mohamed Elshazly, Sultan Sultan Urology Department, Faculty of Medicine, Menoufia University, Menoufia, Egypt
}

*Corresponding Author: Mahmoud Abdelaziz Amer, Mobile: 00201014627286, E-Mail: mahmoud.mousa@med.menofia.edu.eg

\begin{abstract}
Background: Management of renal tumors remains a controversial issue especially in small size tumors or special situations as bilateral disease, single kidney, or compromised renal function, nephron-sparing surgery is the case in such situations.

Objective: Comparing oncological outcome and impact on renal function of open radical nephrectomy and open partial nephrectomy for management of renal tumors.

Patients and methods: Our study was conducted as a non-randomized prospective observational study at the Urology Department, Menoufia University Hospital between December 2018 and June 2020. Forty-eight patients with organconfined renal masses were included in the study. They were divided into two equal groups; (group 1) 24 patients and was treated by PN, and (group 2) 24 patients and was treated by RN.

Results: The mean age of our study is $56.6 \pm 13.2$. Thirty-two patients were males $(66.7 \%)$, while females represented $16(33.3 \%)$. Hot ischemia was done for all partial nephrectomy cases with a mean time of ischemia 13.2 \pm 4.1 . We used different techniques included simple enucleation in 17 patients (70.8\%), polar nephrectomy in 4 patients (16.7\%), and wedge resection in 3 patients (12.5\%). Regarding surgical margin, it was free in 21 patients $(87.5 \%)$ of PN and positive in 3 patients (12.5\%) 2 of them missed follow up and 1 showed no recurrence till now. Our patients showed a smooth postoperative course.

Conclusion: Both techniques (RN\&PN) were comparable in terms of oncological outcomes. Patients tolerated both techniques with no major complications, however partial nephrectomy is advised in the localized renal tumors when technically feasible with less probability of complications and good follow-up data regarding the renal function, the oncological outcome is the same as radical surgery.
\end{abstract}

Keywords: Partial Nephrectomy, Radical Nephrectomy, Renal masses.

\section{INTRODUCTION}

Renal cell carcinoma (RCC) represents about 2$3 \%$ of all cancers and about $85-93 \%$ of malignant tumors of the kidney ${ }^{(\mathbf{1})}$.

RCC is more common in men than in women as $2: 1$, the average age of presentation is fifty to sixty years of life. Smoking, hypertension, and obesity have also been strongly associated with RCC.

Patients with RCC can present with local or systemic symptoms. Local signs and symptoms include hematuria, flank pain, or a palpable abdominal mass. Systemic symptoms can be due to metastases or paraneoplastic syndromes such as hypertension, erythrocytosis, fever, and wasting syndromes ${ }^{(2,3)}$.

$\mathrm{RCC}$ is referred nowadays as the radiologist's tumor as most cases are diagnosed incidentally by ultrasonography and contrast-enhanced urinary CT without any complaint ${ }^{(4)}$.

Treatment options for renal masses include partial nephrectomy $(\mathrm{PN})$, radical nephrectomy $(\mathrm{RN})$, and others (minimal invasive thermal ablative therapies, active surveillance).

Partial nephrectomy is considered a standard surgical treatment for localized renal tumors $\mathrm{T} 1 \mathrm{a}$ and is preferred over radical nephrectomy for $\mathrm{T} 1 \mathrm{~b}$ tumors when technically can be done. For larger T2 tumors radical nephrectomy is still considered the gold standard, but recent data suggest a potential role for partial nephrectomy in selected cases ${ }^{(5,6)}$.

Comparing partial nephrectomy with radical nephrectomy; both have the same surgical outcomes in immediate and long-term follow-up, but radical nephrectomy is associated with more cardiac and metabolic events. Partial nephrectomy is associated with more complications as hemorrhage, urinary leak, long-term follow-up, and recurrence. The most valuable feature of partial nephrectomy over radical is better renal function preservation ${ }^{(7-9)}$.

The present study aimed to compare oncological outcomes and impact on renal function of open radical nephrectomy and open partial nephrectomy for management of renal tumors.

\section{PATIENTS AND METHODS}

Our study was conducted as a non-randomized prospective observational study at the Urology Department, Menoufia University Hospital between December 2018 and June 2020. Forty-eight patients with organ-confined renal masses were included in the study.

Patients were divided into two groups: Group A: open radical nephrectomy 24 patient. Group B: open partial nephrectomy 24 patients. All patients were subjected to detailed medical history and general \& local examination. 
Inclusion criteria: For radical \& partial nephrectomy all fit patients with organ-confined renal mass with sound contralateral kidney of T1 stage.

Exclusion Criteria: For both radical and partial nephrectomy medically unfit patients, patients with coagulopathies, Patients with multiple renal masses, Patients with renal insufficiency and/ or known hypersensitivity for contrast material, and metastatic patients.

\section{Ethical considerations:}

Approval from the Research Ethics committee (REC) was taken before starting fieldwork. All the procedures of the study were approved by the Urology Department of Faculty of Medicine, Menoufia University. Agreement of participant without obligation was taken. Confidentiality of data was preserved. Explanation of this project to the participants was done.

Informed consent was taken from the patients to contribute to the study, after clarifying the aim of the study. This work has been carried out following the Code of Ethics of the World Medical Association (Declaration of Helsinki) for studies involving humans.

Patients were thoroughly assessed by anesthesia staff before surgery with the exclusion of patients with significant cardiac and chest problems.
Operative technique: The patient was placed in the full flank position with lumbar incision, dissection proceeded along with the psoas muscle with anterior elevation of the ureter and/or gonadal vein to identify the renal hilum, the main hilar vessels were circumferentially dissected to allow adequate placement of arterial clamp in case of $\mathrm{RN}$ or bulldog clamp in case of PN.

Intraoperative Variables for partial nephrectomy: We used the open approach in all cases through the flank incision. We used mainly hot ischemia (vascular clamping) alone and ischemia time was calculated by stopwatch. Gerota's fascia was opened in an area far from the tumor to find the capsule, and dissection was performed along the renal capsule until the mass was exposed. The fat was then cleared circumferentially around the mass, allowing for visualization of $1-2 \mathrm{~cm}$ of normal parenchyma for future renal reconstruction. The fat covering the tumor is kept intact or sent separately for histopathological examination. We used the standard clamping technique in which we use Satinsky clamp or bulldogs to temporarily occlude the renal artery. The renal vein was usually not clamped.

We used mainly enucleation for small masses, wedge resection for large exophytic mid zonal masses, and polar nephrectomies in others. (Fig.1:A\&B):

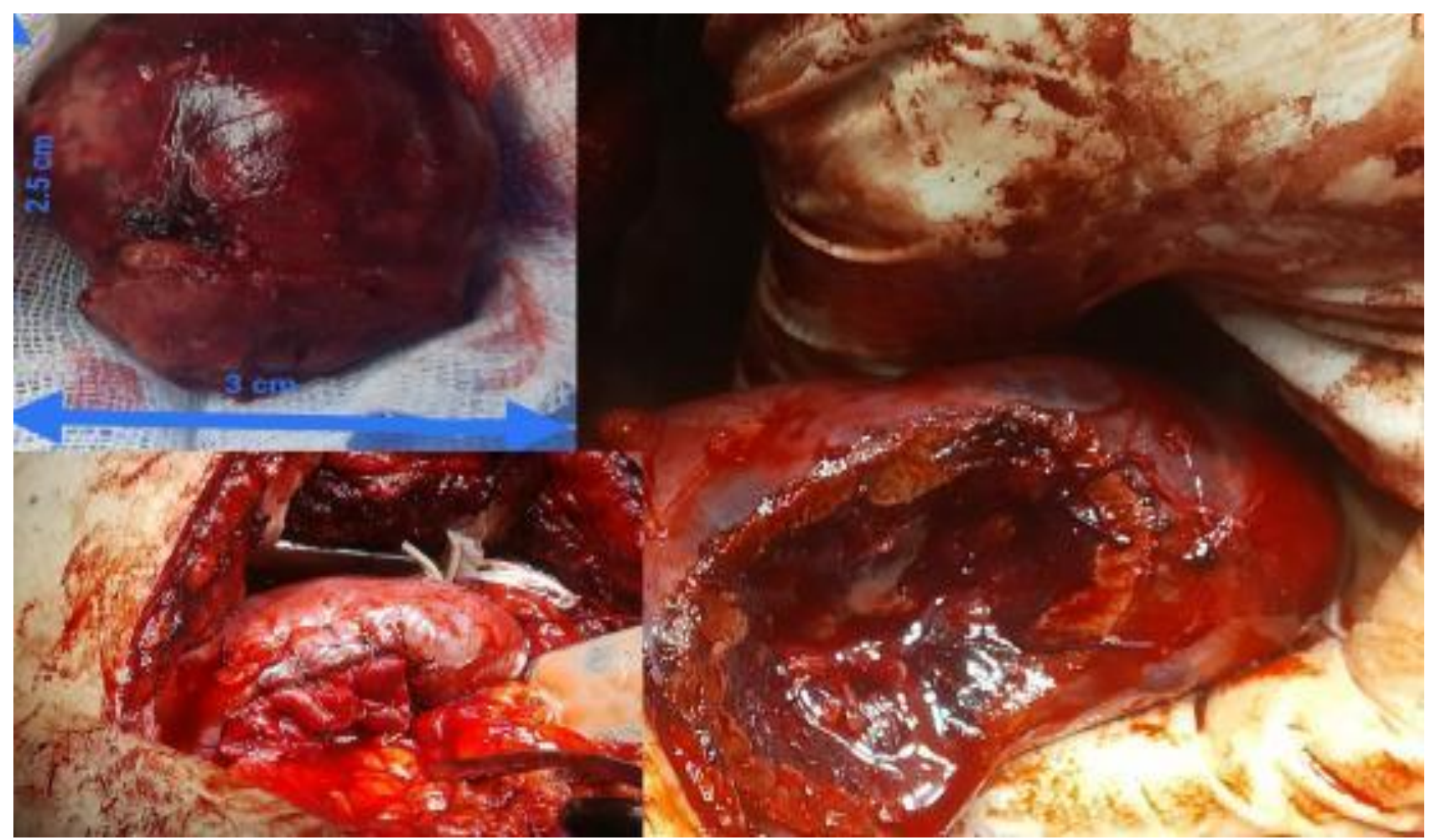

(Fig.1-A): A case of simple enucleation (one of our cases mid zonal exophytic rt renal mass $2.5 \mathrm{X} 3 \mathrm{~cm}$ with good hemostasis) 


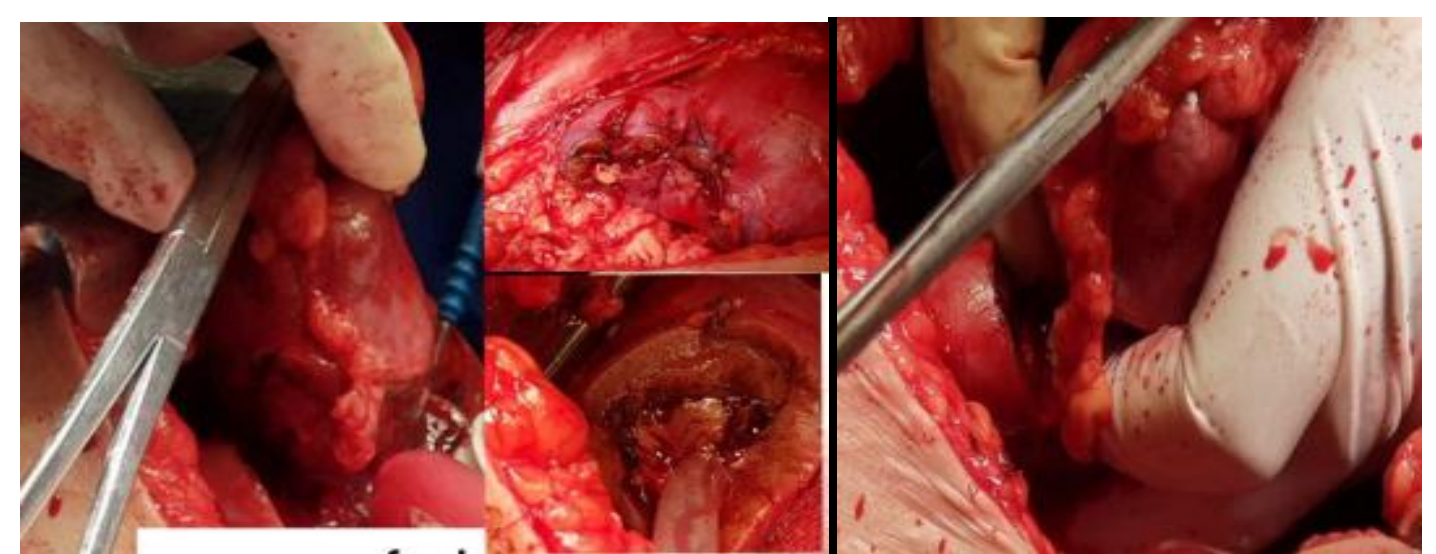

(Fig.1-B): A case of polar nephrectomy (one of our cases lower polar exophytic lt renal mass $5 \mathrm{X} 4 \mathrm{~cm}$ managed by polar nephrectomy). If the pelvicalyceal system was opened, it was closed using vicryl 4/0 sutures, and a suitable length JJ stent was inserted, Hemostasis and renorrhaphy were done using vicryl 0 or 1 suture taking renal capsule on both edges of the defect gel foam in between and Gerota's fascia cover. (Fig.2)

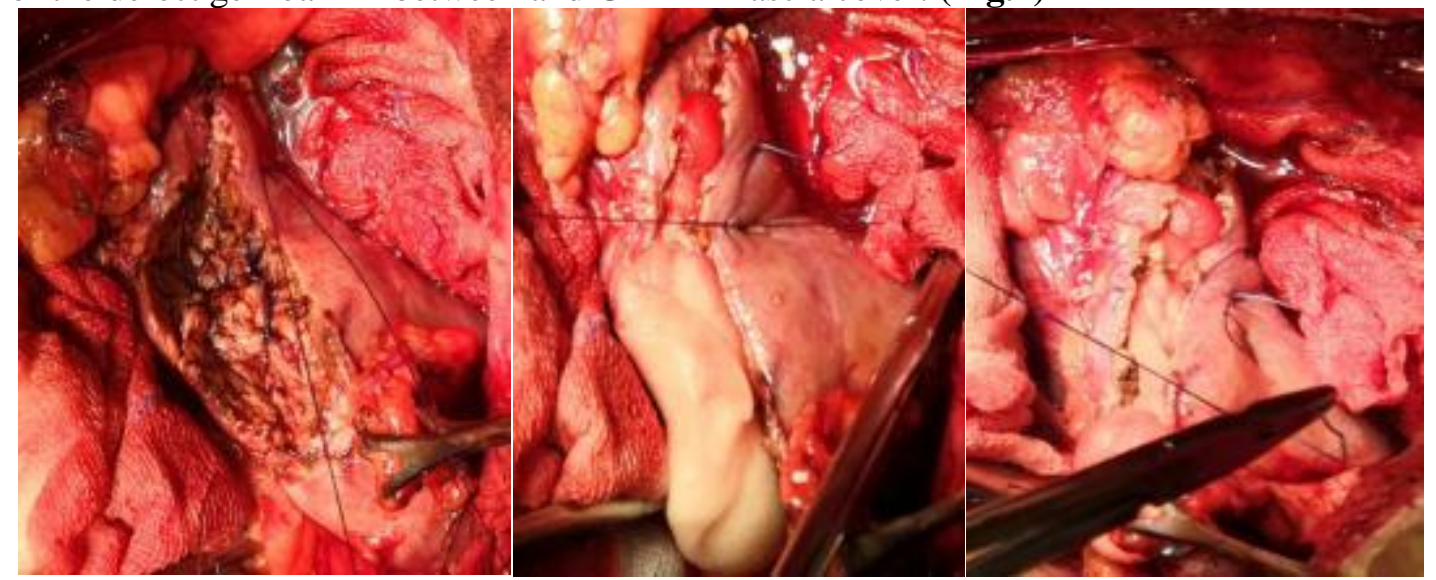

(Fig.2_A) (Fig.2_B) (Fig.2_C). (Fig.2): Closure of surgical bed after PN (Renorrhaphy) using gel foam. (one of our cases of polar nephrectomy leaving a large surgical bed controlled well by hemostasis using vicryl sutures and gel foam).

After surgery, all patients were admitted to the regular ward except if there was a serious medical comorbidity or surgical complications that required an intensive care unit (ICU) admission.

Intravenous fluids, analgesics, antibiotics, and prophylaxis for deep vein thrombosis (DVT) were given in high-risk patients with a dose of $0.5 \mathrm{mg} / \mathrm{KG}$ of low molecular weight heparin (enoxaparin 40mg subcutaneous) $2^{\text {nd }}$ day postoperative and continue for 4 weeks postoperative. Hemoglobin levels, hematocrit, and renal function were monitored postoperatively. The urethral catheter was removed on the second day after surgery and the drain was removed when less than $50 \mathrm{ml}$ per day, early ambulation was encouraged.

Follow-up was scheduled for one week, 3 months, and 6 months. All complications during or after surgery were recorded. A) Functional renal outcomes were assessed by comparison preoperative and postoperative (immediate, three, and six months) serum creatinine and estimated Glomerular Filtration Rate (eGFR). The eGFR was calculated using the Modification of Diet in Renal Disease Study (MDRD) equation: $\mathrm{eGFR}=175 \mathrm{x}\left(\mathrm{S}_{\mathrm{Cr}}\right)^{-}$ ${ }^{1.154} \times(\text { Age })^{-0.203} \times 0.742$ (if female) x 1.212 (if African Descent). B) The oncological outcomes were assessed by: 1) Status of the surgical margin in pathology report after surgery. 2) Contrast-enhanced CT on chest, abdomen, and pelvis for both $\mathrm{RN}$ and $\mathrm{PN}$ cases at 3 and 6 months post-operative to assess tumor recurrence.

\section{Statistical analysis}

Data were collected, tabulated, and statistically analyzed using an IBM-compatible personal computer with Statistical Package for the Social Sciences (SPSS) version 23 (SPSS Inc. Released 2015. IBM SPSS statistics for windows, version 23.0, Armonk, NY: IBM Corp.). Two types of statistical analysis were performed: a) Descriptive statistics e.g. qualitative data were expressed in Number $(\mathrm{N})$, percentage $(\%)$, while quantitative data were expressed as mean $\left(\mathbf{X}^{2}\right)$, standard deviation (SD), and range (minimum-maximum) b) Analytic statistics e.g. Student's t-test, Mann Whitney's test, Paired t-test, Chi-square test, and Fischer's Exact test was used. The significance of the obtained results was judged at the $5 \%$ level $(\mathrm{P}<0.05)$.

\section{RESULTS}

Our study included 48 patients; with a mean age of 56.6 \pm 13.2 . Thirty-two cases were males $(66.7 \%)$, while 16 females represented (33.3\%), and 21 (43.7\%) patients only were smokers.

There was no statistically significant difference between partial and radical nephrectomy groups regarding demographic characteristics ( $\mathrm{p}$-value $<0.05$ ) as shown in table (1). 
Table (1): Socio-demographic characteristics of the studied groups

\begin{tabular}{|c|c|c|c|c|c|c|}
\hline \multirow{2}{*}{ Demographic data } & \multicolumn{2}{|c|}{ PN (N=24) } & \multicolumn{2}{|c|}{$\mathrm{RN}(\mathrm{N}=24)$} & \multirow{2}{*}{$\begin{array}{c}\text { Test of } \\
\text { significance }\end{array}$} & \multirow{2}{*}{ P-value } \\
\hline & $\mathbf{N}$ & $\%$ & $\mathbf{N}$ & $\%$ & & \\
\hline $\begin{array}{l}\text { Age (years): } \\
\text { Mean } \pm \text { SD } \\
\text { Median } \\
\text { Range }\end{array}$ & \multicolumn{2}{|c|}{$\begin{array}{c}55.3 \pm 11.6 \\
53 \\
23-70\end{array}$} & \multicolumn{2}{|c|}{$\begin{array}{c}60.9 \pm 12.7 \\
58.5 \\
38-86\end{array}$} & $\mathbf{t}=1.59$ & 0.118 \\
\hline $\begin{array}{l}\text { Gender: } \\
\text { Female } \\
\text { Male }\end{array}$ & $\begin{array}{c}7 \\
17\end{array}$ & $\begin{array}{l}29.2 \\
70.8\end{array}$ & $\begin{array}{c}9 \\
15\end{array}$ & $\begin{array}{l}37.5 \\
62.5\end{array}$ & $\mathbf{X}^{2}=0.4$ & 0.5 \\
\hline $\begin{array}{l}\text { Special habits: } \\
\text { Smoker } \\
\text { Non-smoker }\end{array}$ & $\begin{array}{l}12 \\
12\end{array}$ & $\begin{array}{l}50 \\
50\end{array}$ & $\begin{array}{c}9 \\
15\end{array}$ & $\begin{array}{l}37.5 \\
62.5\end{array}$ & $\mathbf{X}^{2}=0.8$ & 0.4 \\
\hline
\end{tabular}

PN: partial nephrectomy, RN: radical nephrectomy.

Our patients were presented with haematuria in 5 cases (10.4\%), loin pain in 19 cases (39.5\%), and 24 cases (50\%) were incidentally discovered. Nine patients $(18.7 \%)$ were diabetic, 9 patients $(18.7 \%)$ were hypertensive and 2 patients (4\%) were diabetic and hypertensive. There was no statistically significant difference as regards presentation.

Most of our tumors were polar, 28 cases $(58.3 \%)$ and mid zonal in 20 cases $(41.6 \%)$ with a mean size of $4.2 \pm 1.4$ for PN and a mean size of $5.8 \pm 1.3$ for $\mathrm{RN}$. There was a statistically significant difference as regard tumor size as shown in table (2).

Table (2): Tumor data of the studied groups

\begin{tabular}{|c|c|c|c|c|c|c|}
\hline \multirow[t]{2}{*}{ Tumor data } & \multicolumn{2}{|c|}{ PN (N=24) } & \multicolumn{2}{|c|}{ RN (N=24) } & \multirow{2}{*}{$\begin{array}{c}\text { Test of } \\
\text { significance }\end{array}$} & \multirow[t]{2}{*}{ P-value } \\
\hline & $\mathbf{N}$ & $\%$ & $\mathbf{N}$ & $\%$ & & \\
\hline $\begin{array}{l}\text { Tumor site: } \\
\text { Mid zonal } \\
\text { Polar }\end{array}$ & $\begin{array}{l}10 \\
14\end{array}$ & $\begin{array}{l}41.7 \\
58.3\end{array}$ & $\begin{array}{l}10 \\
14\end{array}$ & $\begin{array}{l}41.7 \\
58.3\end{array}$ & - & - \\
\hline $\begin{array}{l}\text { Size of tumor in CT }(\mathbf{c m}) \\
\text { Mean } \pm \text { SD }\end{array}$ & \multicolumn{2}{|c|}{$4.2 \pm 1.4$} & \multicolumn{2}{|c|}{$5.8 \pm 1.3$} & $\mathbf{U}=3.6$ & $<0.001 * *$ \\
\hline
\end{tabular}

Regarding ischemia type, hot ischemia was done for all partial nephrectomy cases with a mean time of 13.2 44.1. We used different techniques included simple enucleation in 17 patients (70.8\%), polar nephrectomy in 4 patients (16.7\%), and wedge resection in 3 patients (12.5\%). Regarding surgical incision, we used traditional lumbar incision in all patients as shown in table (3).

Table (3): Operative data of the studied groups

\begin{tabular}{|c|c|c|c|c|c|c|}
\hline \multirow[t]{2}{*}{ Operative data } & \multicolumn{2}{|c|}{ PN (N=24) } & \multicolumn{2}{|c|}{$\mathrm{RN}(\mathrm{N}=24)$} & \multirow{2}{*}{$\begin{array}{c}\text { Test of } \\
\text { significance }\end{array}$} & \multirow[t]{2}{*}{ P-value } \\
\hline & $\mathbf{N}$ & $\%$ & $\mathbf{N}$ & $\%$ & & \\
\hline $\begin{array}{l}\text { Time of ischemia } \\
\text { (minutes): } \\
\text { Mean } \pm \text { SD }\end{array}$ & \multicolumn{2}{|c|}{$13.2 \pm 4.1$} & & & \multicolumn{2}{|l|}{ - } \\
\hline $\begin{array}{l}\text { Type of ischemia: } \\
\text { Hot }\end{array}$ & 24 & 100 & \multicolumn{4}{|c|}{ - } \\
\hline $\begin{array}{l}\text { Technique: } \\
\text { Enucleation } \\
\text { Polar nephrectomy } \\
\text { Wedge resection }\end{array}$ & $\begin{array}{r}17 \\
4 \\
3 \\
\end{array}$ & $\begin{array}{l}70.8 \\
16.7 \\
12.5\end{array}$ & \multicolumn{4}{|c|}{-} \\
\hline $\begin{array}{l}\text { Incision \& Position: } \\
\text { Lumbar }\end{array}$ & 24 & 100 & 24 & 100 & $\mathbf{F E}=5.6$ & $0.05^{*}$ \\
\hline
\end{tabular}

Regarding type of RCC; clear cell RCC was the commonest type of RCC in postoperative reports in 24 patients (50\%) followed by chromophobe RCC 7 patients (14.5\%). Regarding surgical margin, it was free in 21 patients $(87.5 \%)$ of $\mathrm{PN}$ and positive in 3 patients (12.5\%) 2 of them missed follow up and 1 showed no recurrence till now. so there was no statistically significant difference between the two groups regarding postoperative pathological criteria. Regarding the pathological stage in radical nephrectomy cases stage, T1b was found to be the commonest in 17 patients $(70.8 \%)$ of $\mathrm{RN}$ cases as shown in table (4). 
Table (4): Pathological data of the studied groups

\begin{tabular}{|c|c|c|c|c|c|c|}
\hline \multirow{2}{*}{ Pathological data } & \multicolumn{2}{|c|}{ PN (N=24) } & \multicolumn{2}{|c|}{$\mathrm{RN}(\mathrm{N}=24)$} & \multirow{2}{*}{$\begin{array}{c}\text { Test of } \\
\text { significance }\end{array}$} & \multirow{2}{*}{ P-value } \\
\hline & $\mathbf{N}$ & $\%$ & $\mathbf{N}$ & $\%$ & & \\
\hline $\begin{array}{l}\text { Pathology: } \\
\text { Chromophobe RCC }\end{array}$ & 4 & 16.7 & 3 & 12.5 & \multirow{4}{*}{$\mathbf{X}^{2}=2.7$} & \multirow{4}{*}{0.4} \\
\hline Clear cell RCC & 14 & 58.3 & 10 & 41.7 & & \\
\hline Papillary RCC & 2 & 8.3 & 2 & 8.3 & & \\
\hline Others & 4 & 16.7 & 9 & 37.5 & & \\
\hline Staging: & \multirow{4}{*}{\multicolumn{2}{|c|}{ - }} & 4 & & \multirow{4}{*}{\multicolumn{2}{|c|}{ - }} \\
\hline T1a & & & $\begin{array}{c}4 \\
17 \\
17\end{array}$ & $\begin{array}{l}16.7 \\
70.8\end{array}$ & & \\
\hline $\mathrm{T} 2 \mathrm{a}$ & & & 1 & 4.2 & & \\
\hline T3a & & & 2 & 8.3 & & \\
\hline Surgical margin: & & & & & \multirow{3}{*}{\multicolumn{2}{|c|}{ - }} \\
\hline Free & 21 & 87.5 & & & & \\
\hline Positive & 3 & 12.5 & & & & \\
\hline
\end{tabular}

Our patients showed smooth postoperative course as 30 patient had no complications while 5 cases (10.4\%) developed wound infection ( 3 cases with PN and 2 cases of RN) controlled by good antibiotics and regular dressing, 2 cases $(4.1 \%)$ developed urinary leakage in cases of PN controlled conservatively without stenting within 14 days, only one case of PN developed AKI and managed conservatively. Regarding scheduled contrast-enhanced CT abdomen and pelvis postoperative; there was no recurrence in cases of PN while there was recurrence in 2 cases $(4.1 \%)$ of $\mathrm{RN}$ as shown in table (5). There was no statistically significant difference between the two groups regarding the postoperative course.

Table (5): Post-operative data of the studied groups

\begin{tabular}{|l|c|c|c|c|c|c|}
\hline \multirow{2}{*}{\multicolumn{1}{c|}{ Post-operative data }} & \multicolumn{2}{|c|}{$\mathbf{P N}(\mathbf{N}=\mathbf{2 4})$} & \multicolumn{2}{c|}{$\mathbf{R N}(\mathbf{N}=\mathbf{2 4})$} & Test of significance & P-value \\
\cline { 2 - 5 } Post-operative & $\mathbf{N}$ & $\mathbf{\%}$ & $\mathbf{N}$ & $\mathbf{\%}$ & & \\
complications: & & & & & & \\
AKI & & & & & & \\
Blood transfusion & 1 & 4.2 & 0 & 0 & & \\
DVT & 0 & 4.2 & 2 & 8.3 & \multirow{2}{*}{$\mathbf{X}^{2}=8.5$} & \\
Fever & 1 & 4.2 & 1 & 4.2 & \\
Ileus & 0 & 0 & 1 & 4.2 & & \\
Malignant ascites & 0 & 0 & 1 & 4.2 & & \\
Stroke & 1 & 4.2 & 0 & 0 & & \\
Urinary leakage & 2 & 8.3 & 0 & 0 & & \\
Wound infection & 3 & 12.5 & 2 & 8.3 & & \\
Died & 0 & 0 & 1 & 4.2 & & \\
No & 15 & 62.5 & 15 & 62.5 & & \\
Follow up CT: & & & & & & \\
Free & 20 & 83.3 & 23 & 95.8 & & \\
Lung metastasis & 0 & 0 & 1 & 4.2 & \multirow{2}{*}{$\mathbf{X}^{2}=5.2$} & \\
Recurrence & 2 & 8.3 & 0 & 0 & & \\
Not done & 2 & 8.3 & 0 & 0 & & \\
\hline
\end{tabular}

The overall results of serum creatinine showed mild change toward the increase in serum level between the two groups PN \&RN and there was no statistically significant difference as shown in table (7). While the pre and postoperative serum creatinine level of each group isolated showed statistically significant difference with high serum creatinine level post-operatively, the RN group showed slightly higher serum creatinine level than the PN group. 
Table (7): Pre and post-operative creatinine in the studied groups

\begin{tabular}{|l|c|c|c|c|}
\hline Creatinine & $\mathbf{P N}(\mathbf{N}=\mathbf{2 4})$ & $\mathbf{R N}(\mathbf{N}=24)$ & $\begin{array}{c}\text { Test of } \\
\text { significance }\end{array}$ & P-value \\
\hline $\begin{array}{l}\text { Creatinine pre } \\
\text { Mean } \pm \text { SD }\end{array}$ & $1.15 \pm 0.31$ & $1.14 \pm 0.27$ & $\mathbf{t}=0.05$ & 0.96 \\
\hline $\begin{array}{l}\text { Creatinine post } \\
\text { Mean } \pm \text { SD }\end{array}$ & $1.26 \pm 0.38$ & $1.35 \pm 0.29$ & $\mathbf{t}=0.9$ & 0.36 \\
\hline
\end{tabular}

The overall results of eGFR showed mild change toward a decrease in the postoperative eGFR between the two groups which was statistically significant in case of the RN group with a mean eGFR of $(57.7 \pm 14.7)$ as shown in table (8). The pre and post-operative eGFR of the PN group isolated showed no statistically significant difference while the pre and post-operative eGFR of the RN group showed a highly significant difference toward a decrease in post-operative eGFR with a decrease of $7 \%$ in case of PN and a decrease of $18 \%$ in case of RN.

Table (8): Pre and post-operative GFR $\left(\mathrm{ml} / \mathrm{min} / 1.73 \mathrm{~m}^{2}\right)$ in the studied groups

\begin{tabular}{|c|c|c|c|c|c|c|}
\hline \multirow[t]{2}{*}{ GFR } & \multicolumn{2}{|c|}{ PN $(\mathrm{N}=24)$} & \multicolumn{2}{|c|}{ RN (N=24) } & \multirow{2}{*}{$\begin{array}{c}\text { Test of } \\
\text { significance }\end{array}$} & \multirow[t]{2}{*}{ P-value } \\
\hline & $\mathbf{N}$ & $\%$ & $\mathbf{N}$ & $\%$ & & \\
\hline $\begin{array}{l}\text { GFR pre } \\
\text { Mean } \pm S D\end{array}$ & \multicolumn{2}{|c|}{$74.8 \pm 11.4$} & \multicolumn{2}{|c|}{$70.6 \pm 18.7$} & $\mathbf{t}=0.7$ & 0.5 \\
\hline $\begin{array}{l}\text { GFR post } \\
\text { Mean } \pm \text { SD }\end{array}$ & \multicolumn{2}{|c|}{$69.04 \pm 11.6$} & \multicolumn{2}{|c|}{$57.7 \pm 12.7$} & $\mathbf{t}=2.1$ & $0.04 *$ \\
\hline
\end{tabular}

\section{DISCISSION}

Renal cell carcinoma (RCC) is considered the ninth most commonly occurring cancer in men and the 14 th most commonly occurring cancer in women. There were over 400,000 new cases in $2018^{\left({ }^{(10)}\right.}$ and represents about $2-3 \%$ of all cancers and about $85-93 \%$ of malignant tumors of the kidney ${ }^{(\mathbf{1})}$.

ORN was the gold standard management for clinically localized renal masses but in the era of NSS, the OPN has been the gold standard NSS ${ }^{(\mathbf{1 1})}$. However, like any other open surgery, OPN is still associated with perioperative complications.

Multiple studies have compared radical and partial nephrectomy for clinically localized renal masses, presenting the potential risks and benefits associated with either approach ${ }^{(\mathbf{1 2})}$.

Current information in the literature about the comparison of ORN and OPN in small renal masses is mainly derived from retrospective articles and systematic reviews ${ }^{(3)}$.

Our study showed a mean age of presentation for cases of RN 61 (38-86) years and 55 (23-70) years for patients who underwent $\mathrm{PN}(\mathrm{P}=0.118)$ this is similar to the results of Stephenson et al. $^{(7)}$ who stated that the mean age is 63 years for RN (17-91) and 60 years for PN (22-83) ( $<$ < 0.001).

The majority of cases were males $32(66.7 \%) 17$ cases $(70.8 \%)$ underwent $\mathrm{PN}$ and 15 cases $(62.5 \%)$ underwent RN, while females represented $16(33.3 \%) 7$ cases (29.2\%) underwent PN, and 9 cases (37.5\%) underwent RN this is close to Antonelli et al. ${ }^{(13)}$ who found that the majority of cases were males 1350 (67.9\%) 747 cases (69.9\%) underwent PN and 603 cases $(65.6 \%)$ underwent RN, while females represented
$637(30.3 \%) 321$ cases $(30.1 \%)$ underwent PN and 316 cases $(34.4 \%)$ underwent RN.

Considering the tumor size, our study showed a mean size of $4.2 \pm 1.4$ for $\mathrm{PN}$ and $5.8 \pm 1.3$ for $\mathrm{RN}$ this is similar to the systematic review which was done by Mir et al. ${ }^{(14)}$ it revealed that tumor size was smaller for PN (weighted mean difference WMD $-1.8 \mathrm{~cm}, 95 \% \mathrm{CI}-3.3$ to $-0.3 ; \mathrm{p}=0.02$ ).

It should be taken into consideration that the mean size of renal tumors that underwent PN in the study of Gill et al. ${ }^{\left({ }^{15}\right)}$ was smaller than our study (33 mm for OPN). In the present study, the mean size was $42 \mathrm{~mm}$ which is highly statistically significant in comparison with RN tumors with P-value $<0.001$.

The ischemia time is an important issue for cases of PN, we used hot ischemia for all cases of PN with a mean time of $13.2 \pm 4.1$ minutes which was slightly shorter than the time estimated by Mina-Riasco et al. (16) which was $20.1 \pm 4.25$ but this was a statistically insignificant difference.

Regarding the pathology of RCC; clear cell RCC was found to be the commonest type of RCC in postoperative reports in 24 patient (50\%) followed by chromophobe RCC 7 patients $(14.5 \%)$ this is close to the study of Kunath et al. ${ }^{(17)}$ which revealed that also clear renal cell carcinoma was the commonest type representing $(67.8 \%)$ of the total cases, followed by chromophobe renal cell carcinoma representing $(11.5 \%)$ of total cases.

Considering the surgical margin it was free in all RN patients while free in 21 patients $(87.5 \%)$ of $\mathrm{PN}$ and positive in 3 patients (12.5\%) so there was no statistically significant difference between the two groups regarding postoperative pathological criteria this is close to Yossepowitch $\boldsymbol{e t}$ al. ${ }^{(18)}$ who found that 
positive surgical margins were documented in 77 patients (5.5\%) Of the PNs and the rest of cases (94.5\%) had negative surgical margin.

Our patients showed smooth postoperative course as 30 patient had no complications while 5 cases (10.4\%) developed wound infection, 2 cases $(4.1 \%)$ developed urinary leakage in cases of PN controlled conservatively without stenting within 14 days, only one case of PN developed AKI and managed conservatively this is close to Mari et al. ${ }^{(19)}$ who found that Persistent urinary leakage was diagnosed in $1.1 \%$ of cases requiring prolonged maintenance of the drain and its manipulation in $0.2 \%$, while $0.9 \%$ required urinary stenting or nephrostomy tube insertion. Postoperative AKI managed with pharmacological treatment was recorded in $2.2 \%$ of cases.

Our study showed overall results of serum creatinine showed mild change toward the increase in serum level between the two groups PN \& RN but there was no statistically significant difference. While the pre and post-operative serum creatinine level of each group isolated showed statistically significant difference with high serum creatinine level postoperatively ( $\mathrm{P}$ value $=0.009)$ for $\mathrm{PN}$ and $(\mathrm{P}$ value $>0.001)$ for $\mathrm{RN}$. RN group showed slightly higher serum creatinine level than PN group this differs from Dash et al. ${ }^{(20)}$ in which serum creatinine 3 months after surgery was available for 182 patients (93\%); the mean values of patients receiving $\mathrm{PN}$ and $\mathrm{RN}$, respectively; the values for the intention-to-treat analysis were 1.45 (SD, 1.73) in 64 patients and $1.59(0.79)$ in 118 .

The increase in creatinine level was significantly smaller in the PN group when analyzing both treatment received (difference between means $0.36 \mathrm{mg} / \mathrm{dL}$; 95\% CI, $0.23-0.48 ; \mathrm{P}<0.001$ by ANOVA) or treatment planned (difference between means $0.23 \mathrm{mg} / \mathrm{dL} ; 95 \%$ CI $0.11-0.34 ; P<0.001)$.

The results were similar for the 6-12 month creatinine measurements (difference between means for treatment planned: $0.21 \mathrm{mg} / \mathrm{dL} ; 95 \%$ CI $0.09-0.33$; $P=0.001)$. There were no important differences between the groups in the delay between surgery and follow-up creatinine level and adding delay as a covariate had no impact on the findings. Thus, PN appeared to diminish the rise in creatinine level after nephrectomy, this difference between the two studies may be due to a longer period of follow-up at that study than our study and also due to a large number of patients.

Considering the GFR, our study showed overall results of eGFR with a mild change toward a decrease in the postoperative eGFR between the two groups it decreased by $7 \%$ in PN and by $18 \%$ in RN .this goes with Choi et al. (21) who found that The risk for developing post-nephrectomy renal insufficiency in patients undergoing radical nephrectomy was higher than that of the patients undergoing partial nephrectomy, while in the study of Wang et al. ${ }^{(22)}$ they found that patients experienced a mean eGFR decrease of $23.8 \%$ immediately postoperative in $\mathrm{PN}$.
Based on the results of the current study, OPN has oncological outcomes similar to those of ORN and slightly better in the preservation of estimated total GFR.

\section{CONCLUSION}

Partial and radical nephrectomies for the treatment of renal tumors are safe and effective techniques with comparable outcomes in terms of oncological and functional items. All patients tolerated both procedures with no major complications. The tumor size and site were important variables in the dictation of either partial or radical nephrectomy.

\section{REFERENCES}

1. Ridge C, Pua B, Madoff D (2014): Epidemiology and staging of renal cell carcinoma. Seminars in Interventional Radiology, 31(1):3-8.

2. Rini B, Campbell S, Escudier B (2009): Renal cell carcinoma. Lancet (London, England), 373(9669):111932.

3. Ljungberg B, Bensalah K, Canfield S et al. (2015): EAU guidelines on renal cell carcinoma: 2014 update. European Urology, 67(5):913-24.

4. Zagoria $\mathbf{R}$ (2000): Imaging of small renal masses: a medical success story. AJR American Journal of Roentgenology, 175(4):945-55.

5. Krabbe L, Bagrodia A, Margulis V et al. (2014): Surgical Management of Renal Cell Carcinoma. Semin Intervent Radiol., 31(1): 27-32.

6. Touijer K, Jacqmin D, Kavoussi L et al. (2010): The expanding role of partial nephrectomy: a critical analysis of indications, results, and complications. European Urology, 57(2):214-22.

7. Stephenson A, Hakimi A Snyder M et al. (2004): Complications of radical and partial nephrectomy in a large contemporary cohort. The Journal of Urology, 171(1):130-4.

8. Anderson B, Potretzke A, Du K et al. (2019): Comparing Off-clamp and On-clamp Robot-assisted Partial Nephrectomy: A Prospective Randomized Trial. Urology, 126:102-9.

9. Lee H, Liss M, Derweesh I (2014): Outcomes of partial nephrectomy for clinical $\mathrm{T} 1 \mathrm{~b}$ and $\mathrm{T} 2$ renal tumors. Current Opinion in Urology, 24(5):448-52.

10. Mahdavifar N, Mohammadian M, Ghoncheh $M$ et al. (2018): Incidence, mortality and risk factors of kidney cancer in the world. World Cancer Research Journal, 5(1):9-14.

11. Huang W, Elkin E, Levey A et al. (2009): Partial nephrectomy versus radical nephrectomy in patients with small renal tumors--is there a difference in mortality and cardiovascular outcomes? The Journal of Urology, 181(1):55-61.

12. Campbell S, Novick A, Belldegrun A et al. (2009): Guideline for the management of the clinical T1 renal mass. The Journal of Urology, 182(4):1271-9.

13. Antonelli A, Ficarra V, Bertini $R$ et al. (2012): Elective partial nephrectomy is equivalent to radical nephrectomy in patients with clinical T1 renal cell carcinoma: results of a retrospective, comparative, multi-institutional study. BJU International, 109(7):1013-8. 
14. Mir M, Derweesh I, Porpiglia F et al. (2017): Partial Nephrectomy Versus Radical Nephrectomy for Clinical T1b and T2 Renal Tumors: A Systematic Review and Meta-analysis of Comparative Studies. European Urology, 71(4):606-17.

15. Gill I, Desai M, Kaouk J et al. (2002): Laparoscopic partial nephrectomy for a renal tumor: duplicating open surgical techniques. The Journal of Urology, 167(2 Pt 1):469-77.

16. Mina-Riascos S, Vitagliano G, García-Perdomo H (2020): Effectiveness and safety of partial nephrectomy - no ischemia vs. warm ischemia: Systematic review and meta-analysis. Investigative and Clinical Urology, 61(5):464.

17. Kunath F, Schmidt S, Krabbe L et al. (2017): Partial nephrectomy versus radical nephrectomy for clinically localized renal masses. The Cochrane Database of Systematic Reviews, 5(5):12045-52.

18. Yossepowitch $\mathrm{O}$, Thompson $\mathrm{R}$, Leibovich $\mathrm{B}$ et al. (2008): Positive surgical margins at partial nephrectomy: predictors and oncological outcomes. The Journal of Urology, 179(6):2158-63.

19. Mari A, Campi R, Schiavina $R$ et al. (2019): Nomogram for predicting the likelihood of postoperative surgical complications in patients treated with partial nephrectomy: a prospective multicentre observational study. Eur Urol., 124(1):93-102.

20. Dash A, Vickers A, Schachter L et al. (2009): Comparison of outcomes in elective partial vs radical nephrectomy for clear cell renal cell carcinoma of 4-7 $\mathrm{cm}$. BJU International, 97(5):939-45.

21. Choi Y, Park Y, Kim Y et al. (2014): Predictive factors for the development of chronic renal insufficiency after renal surgery: a multicenter study. International Urology and Nephrology, 46(4):681-6.

22. Wang R, Wolf J, Wood D et al. (2009): Accuracy of percutaneous core biopsy in the management of small renal masses. Urology, 73(3):586-90. 